\title{
Karakteristik Morfometrik Sapi Aceh, Sapi PO dan Sapi Bali Berdasarkan Analisis Komponen Utama (AKU)
}

\author{
Morphometric Characteristics of Aceh, Ongole Crossbreed and Bali Cattle Based on PCA
}

\author{
Mahmudi $^{1}$, R. Priyanto ${ }^{2}$, \& Jakaria ${ }^{2}$ \\ ${ }^{1}$ Mahasiswa Pascasarjana Program Studi Ilmu Produksi dan Teknologi Peternakan, Fakultas Peternakan, \\ IPB \\ ${ }^{2}$ Departemen Ilmu Produksi dan Teknologi Peternakan, Fakultas Peternakan, IPB \\ Fakultas Peternakan Institut Pertanian Bogor \\ Jln. Agatis, Kampus IPB Dramaga, Bogor, 16680, Indonesia \\ Email koresponden author: ceomudi@gmail.com
}

\begin{abstract}
Aceh cattle is one of four local cattle breeds (Aceh, Bali, Madura, and pesisir), and Ongole crossbreed is also regarded as the local cattle breed in Indonesia. They are most likely to be well adapted to the environment, including disease, climate, feed and water availability. This study aims to determine the body size characteristics of Aceh, Bali, and Ongole crossbreed cattles. As many as 20 heads of Aceh, Bali, and Ongole crossbreed cattle respectively were used for measurement of 18 body parameters. Data obtained was then subkecyed to analysis of variance (ANOVA) and Principle Component Analysis (PCA). The results showed that morphometric measurements of Aceh, Ongole crossbreed, and Bali cattle were significantly different $(\mathrm{P}<\mathbf{0 . 0 5})$. PCA results showed that body measurement was detemined by chest circumference at Bali cattle, neck height at Ongole crossbreed, body length, and chest circumference at Aceh cattle. Meanwhile the shape components were chest widht at Ongole crossbreed and Bali cattle and thoracic part at Aceh cattle. This result should conribute to phenotype profilinge of Bali cattle, Ongole crossbreed, and Aceh cattle, whic is important for cattle breeding and conservation in Indonesia.
\end{abstract}

Keywords : Aceh cattle, Ongole crossbreed cattle, Bali cattle, Morphometric, PCA

\section{PENDAHULUAN}

Berdasarkan keturunan, sapi diklasifikasikan menjadi tiga, yaitu Bos indicus, Bos taurus dan Bos javanicus yang menyebar hampir di seluruh wilayah Indonesia (Payne dan Hodges 1997). Kondisi seperti ini, dimungkinkan terjadinya integrasi antara sapi Bos indicus, Bos taurus dan Bos javanicus (Otsuka et al. 1980). Indonesia memiliki beberapa sumber daya genetik ternak sapi yaitu sapi Bali, Aceh, Sapi PO, Sumba Ongole (SO) dan sapi Madura (Martojo 2003). Bangsa-bangsa sapi tersebut merupakan hasil persilangan antara ketiga kelompok sapi di atas, baik dilakukan secara alami maupun secara sistematik (terprogram). Keragaman bangsa sapi dapat dilihat dari karakteristik sifat yang dapat diamati secara langsung, dimana setiap sifat yang diekspresikan dapat dilihat dari fenotipenya (Noor 2008).

Sapi Aceh merupakan salah satu sumber daya genetik ternak lokal Indonesia yang telah ditetapkan berdasarkan Keputusan Menteri Pertanian Nomor: 2907/KPTS/ OT.140/6/2011. Berdasarkan catatan sejarah bahwa sapi Aceh diduga hasil persilangan dari banteng (Bos javanicus) (Markens 1926) dan diduga kuat juga hasil persilangan antar sapi Bos indicus melalui program ongolisasi. Hal ini dapat dilihat dari karakteristik sapi Aceh yaitu berpunuk (Abdullah et al. 2006). Sapi Aceh memiliki keunggulan yaitu fertilitas tinggi, lebih tahan terhadap kondisi lingkungan yang kurang baik, cepat beradaptasi apabila dihadapkan dengan lingkungan yang baru dan cepat berkembang biak (Umartha 2005), akan tetapi sapi Aceh juga memiliki masalah utama dalam pengembangannya yaitu rendahnya kualitas bibit yang diduga akibat perkawinan silang dalam (inbreeding) dan terjadi program persilangan yang tidak terencana dengan baik. Warwick et al. (1990) menyatakan bahwa perkawinan silang dalam (inbreeding) dapat menurunkan berat badan 2,5 $\mathrm{kg}-5 \mathrm{~kg}$ setiap kenaikan $10 \%$. Untuk menghindari terjadinya kekurangan bibit unggul serta tingginya pemotongan ternak yang berkualias baik pada acara seremonial keagamaan maka perlu di lakukan manajemen pemeliharaan ternak yang baik agar pertumbuhannya lebih cepat. Salah satu tolak ukur produktivitas sapi adalah pertumbuhan, dengan melihat kenyataan tersebut maka upaya pengembangan sapi Aceh perlu ditingkatkan produktivitasnya melalui perbaikan dengan melihat dimensi pertumbuhan melalui kajian karakteristik fenotipe dari sapi Aceh yaitu dengan melakukan kajian morfometrik atau ukuran-ukuran tubuh.

Morfometrik merupakan ukuran-ukuran tubuh seperti tinggi pundak, panjang badan, lingkar dada, berat badan, tinggi pinggul, panjang ekor, panjang telinga 
(Suhaima 1999). Komariah (2016) menyatakan morfometrik merupakan studi yang berhubungan dengan variasi dan perubahan bentuk dan ukuran dari suatu organisme, meliputi pengukaran panjang dan analisa kerangka. Ukuran tubuh ternak sering juga digunakan untuk mengevaluasi pertumbuhan karena ukuran merupakan indikator penting dari pertumbuhan. Pendekatan morfometrik dapat digunakan untuk mempelajari hubungan genetik melalui pengukuran ukuran tubuh (Salamena et al. 2007). Identifikasi morfometrik dengan analisis komponen utama (AKU) untuk menentukan penciri ukuran yang dipengaruhi oleh faktor lingkungan dan penciri bentuk dipengaruhi oleh faktor genetik. Everitt dan Dunn (1998) menyatakan bahwa komponen utama pertama dinyatakan sebagai vektor ukuran, sedangkan komponen utama kedua sebagai vektor bentuk. Selama ini kajian morfometrik pada sapi Aceh belum dilakukan secara komprehensif, oleh karena itu penelitian ini bertujuan menganalisis morfometrik sapi Aceh, sapi Bali dan sapi PO menggunakan analisis komponen utama (AKU).

\section{MATERI DAN METODE}

\section{Lokasi dan Waktu}

Penelitian ini dilaksanakan di BPTU-HPT Sapi Aceh Indrapuri dan IKP-Saree Provinsi Aceh. Penelitian ini dilakukan selama 3 (tiga) bulan dari bulan Maret sampai Mei 2018.

\section{Materi Penelitian}

Materi yang digunakan dalam penelitian ini adalah sapi Aceh, PO dan Bali jantan berumur 18-30 bulan yang dipelihara di BPTU Indrapuri dan di IKP-Saree dengan sebanyak 60 ekor, masing-masing bangsa 20 ekor. Peralatan yang digunakan meliputi peralatan untuk pengukuran perameter tubuh berupa tongkat ukur rondo dan pita ukur, caliper, laptop serta perlatan dokumentasi dan alat tulis.

\section{Peubah Pengamatan}

Peubah morfometrik yang diamati dalam penelitian ini menurut (Gambar 1) adalah :

1. Tinggi pundak diukur dari bagian tertinggi pundak melalui belakang scapula tegak lurus ke tanah dengan menggunakan tongkat ukur,

2. Tinggi pinggul diukur dari bagian tertinggi pinggul secara tegak lurus ke tanah dengan menggunakan tongkat ukur.

3. Lebar pinggul antar tuber ischium kiri dan tuber ischium kanan

4. Panjang badan diukur dari Tuber ischii sampai dengan Tuberositas humeri dengan menggunakan tongkat ukur

5. Dalam dada diukur dari jarak titik tertinggi pundak (gumba) sampai tulang dada dan diukur melalui metatarsal dibelakang siku

6. Lingkar dada diukur melingkar tepat dibelakang scapula dengan menggunakan pita ukur.

7. Lebar dada diukur diantara Tuberositas humeri sinister dan dexter dengan menggunakan tongkat ukur.

8. Panjang kelompok tulang Cervicalis vertebrae diukur dari batas Axio-atlas hingga pangkal leher bagian dorsal. Pada sapi yang berpunuk diukur tepat di depan punuk.

9. Panjang kelompok tulang Thoracic vertebrae diukur dari pangkal leher hingga titik tubuh bagian dorsal.

10. Panjang kelompok tulang Lumbar vertebrae diukur dari titik tengah tubuh bagian dorsal hingga Processus spinosus pertama tulang sacrum.

11. Panjang kelompok tulang Sacral vertebrae diukur sepanjang tulang sacrum

12. Panjang tulang Scapulla diukur dari titik tertinggi tubuh (untuk sapi berpunuk diukur dari pangkal punuk) hingga Tuber humerus

13. Panjang tulang Humerus diukur dari Tuber humerus hingga dititik tengah Tuber radius-ulna.

14. Panjang tulang Radius-ulna diukur dari Tuber radiusulna hingga Os carpal.

15. Panjang tulang Metacarpus diukur dari Os carpal hingga pangkal Os phalank 1

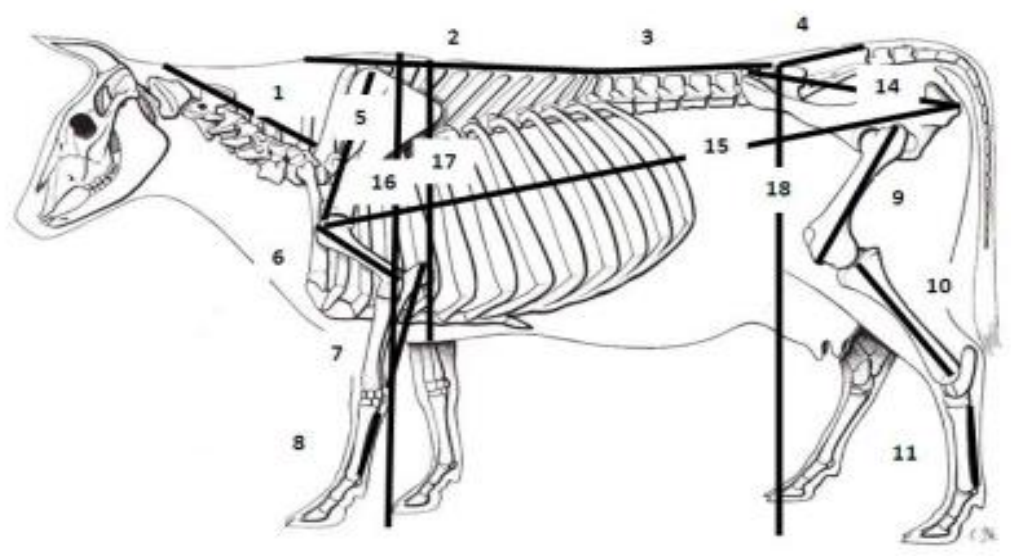

Gambar 1. Bagian-bagian permukaan tubuh sapi yang diamati 
16. Panjang tulang Femur diukur dari Tuber illium hingga Tuber femoris

17. Panjang tulang Tibia-fibulla diukur dari Tuberfemorishingga Tuber calcis

18. Panjang tulang Metatarsal diukur dari pangkal Os tarsus hingga Os phalank1.

Pengukuran bagian-bagian permukaan tubuh tersebut diambil ketika hewan dalam kondisi berdiri normal dengan kepala tegak dan bobot badan bertumpu pada keempat kakinya (Gilbert 1993).

\section{Analisa Data}

Analisis karakteristik morfometrik bangsa sapi Aceh, sapi PO dan Bali menggunakan analisis ragam dengan model matematika (Mattjik dan Sumertajaya 2013) adalah:

$$
\mathrm{Yij}=\mu+\mathrm{ai}+\mathrm{eij}
$$

Keterangan :

Yij = pengamatan morfometrik tubuh pada ternak pada bangsa ternak ke-i, ulangan individu ke-j

$\mu \quad=$ nilai rataan morfometrik tubuh ternak

ai = pengaruh bangsa ternak ke-I dan individu ke $\mathrm{j}$

eij = pengaruh galat percobaan yang berasal dari faktor bangsa ternak ke $\mathrm{i}$ dan ulangan ke $\mathrm{j}$.

Analisis karakteristik morfometrik bangsa sapi Aceh, PO dan Bali menggunakan analisa komponen utama (AKU) persamaan ukuran dan bentuk diturunkan dari matriks kovarian (Gasperz 1992) dengan model matematika adalah :

$$
\mathrm{Yp}=\mathrm{a}_{1 \mathrm{p}} \mathrm{X} 1+\mathrm{a}_{2 \mathrm{p}} \mathrm{X} 2+\mathrm{a}_{3 \mathrm{p}} \mathrm{X} 3+\mathrm{a}_{4 \mathrm{p}} \mathrm{X} 4+\ldots .+\mathrm{a}_{\mathrm{np}} \mathrm{Xn}
$$

Keterangan :

$$
\begin{array}{ll}
\mathrm{Yp} & \text { komponen utama ke-p } \\
\mathrm{a} 1 \mathrm{p}, \mathrm{a} 2 \mathrm{p}, \ldots \mathrm{anp}= & \text { vektor ciri/vektor eigen ke-1,..., n pada } \\
& \text { komponen utama ke-p } \\
\mathrm{X} 1, \mathrm{X} 2, \ldots, \mathrm{Xn}= & \text { peubah-peubah yang diamati }
\end{array}
$$

\section{HASIL DAN PEMBAHASAN}

\section{Karekteristik Ukuran Tubuh}

Hasil analisis morfometrik atau ukuran-ukuran tubuh sapi Aceh umumnya lebih kecil dibandingkan dengan sapi Bali dan sapi PO, sedangkan sapi PO lebih tinggi dibandingkan dengan sapi lainnya (Tabel 1).

Ukuran tubuh ternak dapat berbeda antar satu sama lain yang disebabkan oleh faktor potensi genetik yaitu perbedaan bangsa. Selain itu, Gunawan et al. (2008) menyatakan bahwa selain faktor genetik, perbedaanperbedaan ukuran tubuh yang terjadi juga bisa disebabkan oleh perbedaan lingkungan diantaranya manajemen pemeliharaan, pemeberian pakan dan lokasi pemeliharaan. Lebih lanjut Noor (2008) menyatakan keragaman suatu sifat yang tinggi pada populasi kemungkinan upaya seleksi terhadap sifat tersebut efektif dilaksanakan.

\section{Persamaan Ukuran dan Bentuk}

Persamaan ukuran, persamaan bentuk, keragaman total, dan nilai eigen pada sapi bali, sapi PO dan sapi Aceh di sajikan pada Tabel 2 .

Tabel 2 menyajikan persamaan skor ukuran tubuh sapi Bali memiliki keragaman total ukuran 0,577 \% yang merupakan proporsi keragaman terbesar diantara komponenkomponen yang diperoleh. Nilai eigen yang diperoleh pada persamaan skor ukuran 311,12. Vektor eigen tertinggi pada persamaan ukuran di temukan pada lingkar dada $\left(\mathrm{X}_{6}\right)$ adalah $-0,409$. Persamaan bentuk memiliki keragaman total sebesar $0,713 \%$ yang merupakan proporsi keragaman terbesar setelah keragaman total pada persamaan ukuran. Nilai eigen pada persamaan skor bentuk di temukan sebesar 72,92. Vector eigen tertinggi pada persamaan bentuk ditemukan pada dalam dada $\left(\mathrm{X}_{5}\right)$ sebesar 0,949 yang merupakan penciri bentuk pada sapi bali.

Persamaan skor ukuran tubuh sapi PO yang memiliki keragaman total sebesar 0,852\% merupakan proporsi keragaman terbesar diantara komponen-komponen utama yang diperoleh. Nilai eigen yang diperoleh pada persamaan skor ukuran 1801,4 , vektor eigen tertinggi pada persamaan ukuran di temukan pada tinggi pundak $\left(\mathrm{X}_{1}\right)$ sebesar $-0,962$ merupakan penciri ukuran sapi PO. Persamaan bentuk memiliki keragaman total sebesar 0,941\% yang merupakan proporsi keragaman terbesar setelah keragaman total pada persamaan ukuran. Nilai eigen pada persamaan skor bentuk ditemukan pada dalam dada $\left(\mathrm{X}_{5}\right)$ sebesar -0,847 merupakan penciri bentuk pada sapi PO.

Persamaan skor ukuran tubuh pada sapi Aceh yang memiliki keragaman total sebesar 0,997 \% merupakan proporsi keragaman terbesar di antara komponen-komponen utama yang diperoleh. Nilai eigen yang diperoleh pada persamaan skor ukuran 586,51, vektor eigen tertinggi pada persamaan ukuran ditemukan pada panjang badan $\left(\mathrm{X}_{2}\right)$ sebesar 0,597 merupakan penciri ukuran sapi Aceh. Persamaan bentuk memiliki keragaman total sebesar 0,998 \% yang merupakan proporsi keragaman terbesar setelah keragaman total pada persamaan ukuran. Nilai eigen pada persamaan skor bentuk ditemukan pada bagian thoracic $\left(\mathrm{X}_{9}\right)$ sebesar 0,845 merupakan penciri bentuk sapi Aceh.

Perbedaan ukuran maupun bentuk pada ketiga bangsa sapi tersebut kemungkinan disebabkan oleh adanya perbedaan faktor genetik dan manajemen pemeliharaan, Gunawan et al. (2008) mengemukakan bahwa selain faktor genetik, terjadinya pebedaan ukuran tubuh disebabkan oleh faktor perbedaan lingkungan di antaranya menajemen pemeliharaan. Perbedaan ukuran tubuh antara sapi Bali, sapi Aceh dan sapi PO juga sebelumnya dilaporkan oleh Pane (1991), sedangkan bentuk tubuh atau yang dicirikan dengan keragaman total komponen ke-2 merupakan karakteristik yang khas antara masing-masing bangsa sapi yang diamati.

Hasil ini menunjukkan bawa penciri ukuran dan bentuk antara sapi Bali, sapi PO dan sapi Aceh berbedabeda. Namun terlihat terdapat persamaan antara penciri bentuk sapi Bali dan Sapi PO. Pada sapi Bali penciri ukuran yaitu lingkar dada dan penciri bentuk dalam dada lebih tinggi dibandingkan dengan sapi PO dan Sapi Aceh, pada sapi PO penciri ukuran yaitu tinggi pundak lebih tinggi di bandingkan sapi Bali dan sapi Aceh sedangkan penciri bentuk dalam dada sama dengan sapi Bali. Sedangkan pada sapi Aceh penciri ukuran yaitu panjang badan lebih tinggi dibandingkan dengan sapi Aceh dan sapi PO, pada penciri bentuk yaitu thorachic lebih tinggi dibandingkan sapi Bali 
Mahmudi et al.

Jurnal Ilmu Produksi dan Teknologi Hasil Peternakan 7 (1): 35-40

Tabel 1. Rataan, standar deviasi variabel-variabel linear ukuran tubuh

\begin{tabular}{|c|c|c|c|c|}
\hline \multirow[t]{2}{*}{ No } & \multirow[t]{2}{*}{ Parameter } & Aceh & Bali & $\mathrm{PO}$ \\
\hline & & rataan $\pm S D(n=20)$ & rataan $\pm \mathrm{SD}(\mathrm{n}=20)$ & rataan $\pm \mathrm{SD}(\mathrm{n}=20)$ \\
\hline 1 & Tinggi Pundak & $110,175 \pm 6,14 \mathrm{ab}$ & $107,9 \pm 6,94 b$ & $124,45 \pm 40,84 a$ \\
\hline 2 & Panjang Badan & $110,95 \pm 15,28 \mathrm{a}$ & $110,8 \pm 6,79 a$ & $109,85 \pm 6,52 a$ \\
\hline 3 & Tinggi Pinggul & $112,925 \pm 7,49 a$ & $109,35 \pm 7,18 \mathrm{a}$ & $112,1 \pm 1,94 a$ \\
\hline 4 & Lebar Pinggul & $32,425 \pm 4,21 b$ & $30,95 \pm 2,11 b$ & $34,65 \pm 2,62 a$ \\
\hline 5 & Dalam dada & $55,1 \pm 4,98 b$ & $63,05 \pm 8,39 a$ & $63,3 \pm 12,22 a$ \\
\hline 6 & Lingkar dada & $143,15 \pm 14,40 \mathrm{a}$ & $144,3 \pm 9,44 a$ & $144,95 \pm 6,43 a$ \\
\hline 7 & Lebar dada & $30,45 \pm 6,24 a$ & $29,95 \pm 4,45 \mathrm{a}$ & $27,7 \pm 4,46 a$ \\
\hline 8 & Cervical & $21,85 \pm 3,28 b$ & $32,75 \pm 5,81 \mathrm{a}$ & $32 \pm 4,29 \mathrm{a}$ \\
\hline 9 & Thoracic & $39,135 \pm 11,07 a$ & $35,05 \pm 7,19 \mathrm{a}$ & $40 \pm 5,11 \mathrm{a}$ \\
\hline 10 & Lumbar & $29,55 \pm 3,58 b$ & $32,05 \pm 4,45 \mathrm{ab}$ & $34,3 \pm 3,83 a$ \\
\hline 11 & Sacral & $23,025 \pm 2,76 \mathrm{c}$ & $25,65 \pm 2,91 b$ & $27,45 \pm 2,56 \mathrm{a}$ \\
\hline 12 & Scapulla & $38,55 \pm 6,31 b$ & $44,3 \pm 4,07 \mathrm{a}$ & $41,95 \pm 3,90 \mathrm{a}$ \\
\hline 13 & Humerus & $28,3 \pm 3,54 c$ & $31,5 \pm 2,67 b$ & $33,9 \pm 3,19 a$ \\
\hline 14 & Radius-Ulna & $28,775 \pm 5,72 c$ & $32,65 \pm 1,76 b$ & $37,9 \pm 2,47 a$ \\
\hline 15 & Metacarpal & $21,3 \pm 1,26 b$ & $24,85 \pm 4,96 \mathrm{a}$ & $25,55 \pm 1,61 \mathrm{a}$ \\
\hline 16 & Femur & $29,625 \pm 2,80 \mathrm{c}$ & $33,3 \pm 3,03 b$ & $41,35 \pm 6,58 \mathrm{a}$ \\
\hline 17 & Tibia Fibula & $35,65 \pm 2,43 b$ & $39,2 \pm 3,68 \mathrm{a}$ & $40 \pm 5,13 \mathrm{a}$ \\
\hline 18 & Metatarsal & $24,475 \pm 2,57 b$ & $31,1 \pm 4,64 a$ & $30,5 \pm 3,76 a$ \\
\hline
\end{tabular}

Huruf yang berbeda pada kolom yang sama menyatakan berbeda nyata $(\mathrm{P}<0,05), \mathrm{SD}=$ Standar Deviasi

Tabel 2. Persamaan Ukuran dan Bentuk

\begin{tabular}{|c|c|c|c|c|}
\hline Populasi & & Persamaan & Keragaman Total \% & Nilai Eigen \\
\hline \multirow[t]{8}{*}{ Bali } & Ukuran & $-0,360 \times 1+-0,302 \times 2+-0,368 \times 3+-0,021 \times 4+0,076 \times 5+$ & 0,577 & 311,12 \\
\hline & & $-0,409 \times 6+-0,200 \times 7+-0,281 \times 8+-0,386 \times 9+-0,197 \times 10+$ & & \\
\hline & & $-0,002 \times 11+-0,111 \times 12+-0,102 \times 13+-0,007 \times 14+-0,268 \times 15+$ & & \\
\hline & & $0,102 \times 16+-0,076 \times 17+-0,229 \times 18$ & & \\
\hline & Bentuk & $0,069 \times 1+0,086 \times 2+-0,022 \times 3+-0,004 \times 4+-0,949 \times 5+$ & 0,713 & 72,92 \\
\hline & & $-0,264 \times 6+-0,012 \times 7+0,064 \times 8+-0,021 \times 9+-0,08 \times 10+$ & & \\
\hline & & $-0,019 \times 11+-0,031 \times 12+0,009 \times 13+0,014 \times 14+0,024 \times 15+$ & & \\
\hline & & $-0,013 \times 16+-0,063 \times 17+0,003 \times 18$ & & \\
\hline \multirow[t]{8}{*}{$\mathrm{PO}$} & Ukuran & $-0,962 \times 1+0,121 \times 2+-0,020 \times 3+-0,029 \times 4+0,073 \times 5+$ & 0,852 & 1801,4 \\
\hline & & $-0,114 \times 6+0,076 \times 7+0,047 \times 8+-0,114 \times 9+-0,003 \times 10+$ & & \\
\hline & & $0,005 \times 11+-0,006 \times 12+0,019 \times 13+0,010 \times 14+0,005 \times 15+$ & & \\
\hline & & $-0,100 \times 16+0,092 \times 17+-0,013 \times 18$ & & \\
\hline & Bentuk & $-0,05 \times 1+0,045 \times 2+0,039 \times 3+-0,006 \times 4+-0,847 \times 5+$ & 0,941 & 190,1 \\
\hline & & $-0,224 \times 6+-0,119 \times 7+0,118 \times 8+-0,077 \times 9+-0,168 \times 10+$ & & \\
\hline & & $0,057 \times 11+-0,272 \times 12+0,107 \times 13+-0,028 \times 14+-0,065 \times 15+$ & & \\
\hline & & $0,229 \times 16+-0,065 \times 17+-0,116 \times 18$ & & \\
\hline \multirow[t]{8}{*}{ Aceh } & Ukuran & $0,228 \times 1+0,597 \times 2+0,258 \times 3+0,164 \times 4+0,184 \times 5+$ & 0,997 & 586,51 \\
\hline & & $0,553 \times 6+0,210 \times 7+0,019 \times 8+0,146 \times 9+0,061 \times 10+$ & & \\
\hline & & $0,073 \times 11+0,243 \times 12+0,100 \times 13+0,086 \times 14+0,016 \times 15+$ & & \\
\hline & & $0,083 \times 16+-0,004 \times 17+0,020 \times 18$ & & \\
\hline & Bentuk & $-0,062 \times 1+0,095 \times 2+0,032 \times 3+-0,037 \times 4+-0,133 \times 5+$ & 0,998 & 146,96 \\
\hline & & $-0,157 \times 6+-0,007 \times 7+-0,068 \times 8+0,845 \times 9+-0,156 \times 10+$ & & \\
\hline & & $-0,000 \times 11+-0,126 \times 12+0,138 \times 13+-0,386 \times 14+0,040 \times 15+$ & & \\
\hline & & $0,042 \times 16+-0,066 \times 17+0,092 \times 18$ & & \\
\hline
\end{tabular}


Tabel 3. Rekapitulasi penciri ukuran dan bentuk tubuh

\begin{tabular}{lll}
\hline Bangsa & Penciri Ukuran & Penciri Bentuk \\
\hline Sapi Bali & Lingkar Dada (X6) & Dalam dada (X5) \\
Sapi PO & Tinggi Pundak (X1) & Dalam dada (X5) \\
Sapi Aceh & Panjang Badan (X2) & Thoracic (X9) \\
\hline
\end{tabular}

dan PO.

Visualisasi penciri ukuran dan bentuk tubuh berdasarkan hasil analisis komponen utama (AKU) sapi Aceh, Bali dan PO di sajikan pada Gambar 2. Berdasarkan diagram kerumunan Sapi Aceh, Bali dan PO memiliki skor ukuran yang berbeda antar tiga bangsa. Sapi Bali memiliki skor ukuran di bagian lingkar dada, sementara pada sapi PO dan sapi Aceh skor masing-masing di bagian tinggi pundak dan panjang badan. Hal ini diperlihatkan pada kerumunan Gambar 2. Diagram kerumunan skor bentuk memiliki ukuran yang relatif sama antara sapi Bali dan Sapi PO terdapat pada bagian dalam dada, sedangkan pada sapi Aceh skor bentuk terdapat dibagian thoracic. Skor bentuk yang sama diduga menunjukkan bahwa secara genetik ketiga kelompok bangsa sapi tersebut memiliki kesamaan bentuk (fenotipik) yang dipengaruhi faktor genetik dan lingkungan (Hardjosubroto 1998).

\section{KESIMPULAN}

Berdasarkan hasil yang diperoleh secara umum morfometrik sapi Aceh lebih kecil dibandingkan dengan sapi Bali dan sapi PO. Berdasarkan hasil analisis komponen utama (AKU) bahwa lingkar dada merupakan penciri ukuran dan dalam dada sebagai penciri bentuk pada sapi Bali, tinggi pundak penciri ukuran dan dalam dada sebagai penciri bentuk pada sapi PO, sedangkan panjang badan penciri ukuran dan thorachic sebagai penciri bentuk pada sapi Aceh. Dengan demikian bahwa morfometrik dapat digunakan sebagai stategi dalam program perbaikan produktivitas khususnya sapi Aceh.

\section{Saran}

Berdasarkan hasil penelitian, morfometrik dapat digunakan sebagai salah satu indikator dalam peningkatan produktivitas khususnya sapi Aceh. Seleksi terhadap peubah-peubah penentu baik ukuran dan bentuk perlu dilakukan terutama di pusat pembibitan sapi Aceh.

\section{DAFTAR PUSTAKA}

Abdullah, Man RR, Noor H, Martojo DD, Solihin, Hendirawan E. 2006. Keragaman fenotipik sapi Aceh di Nanggroe Aceh Darussalam. J. Indon. Trop. Anim. Agric., 32: 11-21. Anim. Sci., Bogor Agric., Indonesia.

Direktorat Jenderal Peternakan dan Kesehatan Hewan. 2013. Statistik Peternakan dan Kesehatan Hewan. Jakarta (ID): Direktorat Jenderal Peternakan dan Kesehatan Hewan.

Everitt BS \& Dunn G. 1998. Applied Multivariate Data Analysis. Jhon Wiley and SonsInc., Illionois.

Gazpersz V. 1992. Teknik Analisi dalam Penelitian Percobaan. Tarsito, Bandung

Hardjosubroto W. 1998. Kerbau: Mutiara yang Terlupakan. Yogyakarta (ID): UGM Pr.

Kementerian Pertanian Republik Indonesia. 2015. Peraturan Menteri PertanianNomor 46/Permentan/ PK.210/8/2015 tentang Budidaya Sapi Potong yang Baik. Jakarta (ID): Kementerian Pertanian Republik Indonesia.

Komariah. 2016. Produktivitas kerbau lumpur berdasarkan agrosistem dan strategi pengembangannya di Kabupaten Cianjur [tesis]. Bogor (ID): Institut Pertanian Bogor.

Martojo H. 2003. Indigenous Bali Cattle: The Best Suited Cattle Breed for Sustainable Small Farms in Indonesia. Laboratory of Animal Breeding and Genetics, Faculty of Animal Science, Bogor Agricultural University, Indonesia.

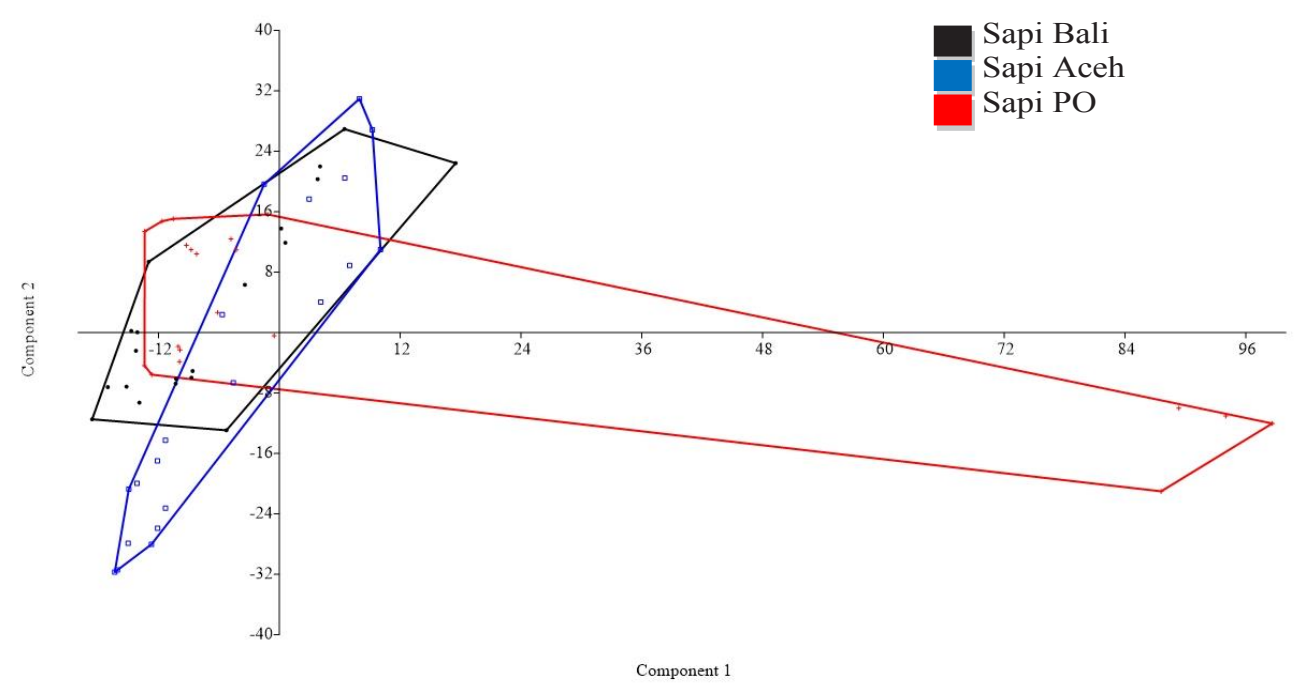

Gambar 2. Diagram kerumunan data skor ukuran dan bentuk sapi Bali, sapi PO dan sapi Aceh berdasarkan analisis komponen utama (AKU) 
MattjikAA, Sumertajaya IM. 2013. Perancangan Percobaan dengan Aplikasi SAS dan Minitab Jilid I. Bogor (ID): IPB Press.

Noor RR. 2008. Genetika Ternak. Penebar Swadaya, Jakarta.

Otsuka J, Kondo, Simamora, Mansjoer, Martojo. 1980. Body Measurement of the Indonesian Native Cattle. In the Origin and Phylogeny of Indonesian Native Livestock. The Research group of Overseas Scientific Survey.

Pane I. 1991. Produktivitas dan Breeding Sapi Bali. Prosiding Seminar Nasional Sapi Bali. 2-3 September 1991. Fakultas Peternakan Universitas Hassanudin. Ujung Pandang, hlm : 50

Pusat Kajian Sapi Bali. 2012. Sapi Bali Sumberdaya Genetik Asli Indonesia, Universitas Udayana, Denpasar.
Riady M. 2004. Tantangan dan Peluang Peningkatan Produksi Sapi Potong menuju 2020. Prosiding Lokakarya Nasional Sapi Potong. Yogyakarta, 89 Okt 2004. Bogor : Pusat Penelitian dan Pengembangan Peternakan. Badan Penelitian dan Pengembangan Pertanian. Hlm 3-6.

Salamena JF, Noor, Sumantri C dan Inounu. 2007. Hubungan genetik, ukuran populasi efektif dan laju silang dalam per generasi populasi domba di Pulau Kisar. J. Indon. Trop. Anim. Agric. 32 [2]: 71-75.

Santosa U. 2008. Mengelola Peternakan Sapi secara Profesional. Jakarta (ID): Penebar Swadaya.

Warwick, Astutik, Hardjosubroto.1990. Pemuliaan Ternak. Gadjah Mada University Press, Yogyakarta. (PO). Jakarta (ID). 